\title{
Susan W. Woolley, Lee Airton (eds.). Teaching about Gender Diversity. Teacher-Tested Lesson Plans for K-12 classrooms. Toronto 2020: Canadian Scholars. Pp. 334.
}

Without any doubts, we live in different times with still quite closed-minded approach towards teaching about gender diversity. In Poland no less, this particular topic is paved over in course books and ministry guidelines for primary and secondary schools. That is why, as teachers and academics we can benefit by reading this unputdownable publication published by Canadian Scholars Press in 2020. An attractive aspect of the book is that the authors focused not only on a theoretical perspective but also in collaboration with several scientists they managed to create lesson plans suitable for children in K-12 classrooms.

Teaching about diversity is one of the few books that was written by openly queer and non-binary transgender teachers and academics. The editors are not only the members of the local community members but also teacher education who mainly focus themselves in preservice teacher education programs across Canada and the USA. The publication is deeply embedded in Indigenous lands history and those people's devastating life experience as some of the authors are currently living and working on the traditional lands. According to the writers the main idea of this publication is not only to educate but to „create a book grounded in a contextually specific, historicised, and non-binary conceptualisation of gender diversity because beginning (but not only beginning) teachers must recognise that the gender-based oppression, in institutionalised education on the land where we live” (Woolley \& Airton, 2020, p. 8). Besides, by this book they thirst for „gender diversity curriculum" which could be the answer for the visible lack of basic information about transgender people in modern society. But, first and foremost, to teach about gender diversity through proposed lesson plans that aim to do both of these things.

The title is divided into three sections targeting different grade levels: Elementary (K-5), Middle Years (6-9), Secondary (10-12). Each of them apart from the useful theoretical and scientific compendium on the important topic which is gender itself. The second component, lessons plans were designed to support learning and teaching about diversity which might be a concept that some of the teachers are not familiar with. Teaching materials cover a wide range of topics, texts and innovative approaches to educating about gender diversity. To provide for the teachers high quality of this academic source, all of the plans were subjected to a double-blind review process and went through multiple rounds of re- 
visions based on the reviewers' feedback. The whole bit was done to pay careful attention to the pedagogy and the audacious topics that were handled.

The wide introduction to teaching about gender diversity written by Lee Airton and Susan W. Woolley is just much more than the book opening. From the first page to the last one in this part, we can read why this volume matters and how to use it in everyday teaching practice. The reader will not only have the grasp to understand the meaning of gender diversity but what is more, get the idea of how to create a positive classroom climate for this work. Moreover, the authors managed to present theories that are major contributions to their understanding of gender: poststructuralism, transgender studies, postcolonial theory as well as black feminist thought.

One of the most important parts of this publication is the first section dedicated to the elementary level. The major topics touched on are gender stereotypes, categories and identity. Interestingly authors prepared a series of lessons that by read-aloud early literacy picture books with gender-neutral language engage students and teach them gender terminology. An exception is a lesson plan particularly intended for Catholic elementary school teachers which present gender diversity as congruent with aspects of Catholic doctrine.

The second part underlines the crucial role of puberty and illustrates the middle years' students reflection on their experiences of gender. The lessons plans include the use of visual arts in exploring gender representation in popular culture and challenge categories of gender presented with ways they are used in data collection and analysis.

After these first two chapters, the book takes a topical organisation to features lesson plans encouraging teachers to perceive gender at a variety of levels (ex. personal, historical, structural and cross-cultural). Again, the main idea is to critically discuss the representations of gender and gender stereotypes but this time with a deeper sense of understanding. The editors cover a broader range of content and introduce new topic focused on transgender people across time and culture. All of this is a treasure of practical suggestions presented with remarkable insight and creativity of authors.

The Teaching about Gender Diversity does an excellent job in describing, explaining and relating the research literature to actual teaching practice, and it does so in ways that are both innovative and transparent. Overall, the editors did an admirable job of achieving goals set up and presented at the beginning of this book. The most important message of this publication is that gender diversity should be integrating and thought within the curriculum on daily basis, rather than „a prescription for the classes in which such lessons should be taught" (Woolley \& Airton, 2020, p. 10). 


\section{REFERENCES}

WOOLLEY, S. \& AIRTON, L. (2020) Teaching about Gender Diversity: Teacher-Tested Lesson Plans for K-12 Classrooms. Toronto: Canadian Scholars.

Jakub Adamczewski

Adam Mickiewicz University, Poznan (Poland)

ORCID: 0000-0002-0152-3159 